\title{
Quality and Safety Competencies in Undergraduate Nursing Education: Where are we now?
}

\author{
Jennifer Bryer* \& Virginia Peterson Graziose \\ Farmingdale State College, Farmingdale, NY, USA \\ *Corresponding Author - Jennifer Bryer, Farmingdale State College, Farmingdale, NY, USA. Email: bryerj@ farmingdale.edu \\ DOI: https://dx.doi.org/10.47988/janany.70643191.1.1
}

\begin{abstract}
BACKGROUND: Medical errors are the third leading cause of death in the United States. To address this problem, a concerted effort by nurse educators to integrate Quality and Safety Education for Nurses (QSEN) competencies into nursing curricula is relevant. There is a need for innovative educational strategies, faculty development, and implementation approaches to support successful QSEN competency implementation.
\end{abstract}

PURPOSE: The purpose of this research was to evaluate a faculty development course that included QSEN competency education, resources, and support.

METHODS: A pretest posttest design was used and 19 nursing faculty from a northeast U.S. public college participated in the program. Participants completed the National QSEN Faculty Survey before and after a 6-part QSEN competency-based training course. Descriptive statistics and the chi-square statistical test were used to compare means of pretest and post-test responses.

RESULTS: Results indicated a significant increase of incorporating the QSEN competencies in nursing courses following the faculty development program. The most helpful QSEN resource was found to be the QSEN website followed by the Institute for Healthcare Improvement (IHI) in pre and post-test results. Case studies, lectures, and group projects were the most frequently used teaching strategies, and the classroom was found to be the setting where most faculty integrated QSEN competencies into their courses.

IMPLICATIONS: Faculty development programs are an effective method of providing support for the integration of QSEN competencies into the undergraduate nursing curricula. Evaluation of faculty development programs is essential so that effective programs can be shared and sustained.

Keywords: QSEN, competencies, faculty development, quality, safety

Funding: The authors were recipients of the Theresa Santmann Faculty Development Award (February, 2020).

Conflict of Interest: The authors declare no actual or potential conflict of interest. 


\section{Quality and Safety Competencies in Undergraduate Nursing Education: Where are we now?}

The pace and scale of improvement in patient safety has been slow and limited. The reality is that medical errors are the third leading cause of death in the United States (Makary \& Daniel, 2016). Dating back to the Institute of Medicine's (now the National Academy of Medicine) 2001 report, data indicate a steady increase in the number of lives lost each year to preventable errors. Recognizing the need to improve patient outcomes, the Quality and Safety for Nurses (QSEN) initiative was developed to address the challenge of preparing future nurses with the knowledge, skills, and attitudes (KSAs) necessary to continuously improve the quality and safety of the healthcare systems within which they work (Sullivan, Hirst \& Cronenwett, 2009). Early QSEN research focused on the development of six competencies: safety, teamwork and collaboration, informatics, quality improvement, evidencebased practice, and patient centered care that were considered an essential part of nursing curricula, faculty development, and nursing education. As a result, nursing programs across the U.S. began integrating quality and safety content throughout their curricula. Despite efforts by nurse educators, students did not perceive that this content was integrated throughout their nursing program (Peterson-Graziose \& Bryer, 2017). In addition, nurse educators felt unprepared to teach quality and safety content in a way that reflected current evidence-based practice. Research indicates the need for educational strategies, faculty development and support to facilitate meaningful integration of the QSEN competencies across nursing curricula (Altmiller \& Armstrong, 2017).

\section{Literature Review}

Research suggests inconsistencies in the number of faculty trained and differences in preparation to teach QSEN competencies among nurse educators. In a study by Disch, Barnsteiner, and McGuinn (2013), an evaluation of the QSEN impact on curricula in six nursing schools found varying degrees of implementation of the six competencies. Two major factors associated with the degree of implementation were the stability and support of leadership and access to resources. Lewis and Lamb (2011) found that increasing faculty knowledge and skills, and faculty willingness to learn are vital to the integration of QSEN competencies into nursing curricula. In a later study of 252 DNP programs in the United States, 117 faculty indicated that they were skilled, but not proficient in quality improvement strategies. In addition, qualitative results found that DNP faculty found the need for quality improvement and QSEN refresher programs (Tovar et al., 2019).

A study of over 1,100 nursing faculty examined the diffusion of QSEN competencies across schools of nursing (Barnsteiner et al., 2012). Results indicated differences in the level of integration based on the competency. Quality improvement and informatics had lower levels of integration than evidence-based practice, teamwork and collaboration, safety, and patient-centered care (Barnsteiner et al., 2012). A systematic review of the literature by Cengiz and Yoda (2020) revealed that students feel more prepared to perform patient centered care skills and least prepared to perform quality improvement.

Limited resources, lack of knowledge about the competency and unfamiliarity with core measures were cited by faculty as reasons for limited integration of the two competencies. An assessment of quality and safety education in nursing (Pollard et al., 2014) found that faculty rated themselves as either expert or having some comfort in teaching the QSEN competencies. However, they were least comfortable teaching quality improvement and informatics. All study participants agreed that they wanted more information and education in the areas of evidence-based practice and quality improvement. The 2017 National QSEN Faculty Survey was used to examine faculty needs related to the integration of QSEN in nursing curricula (Altmiller \& Sullivan, 2017). Results reflect that the QSEN competencies were integrated to some degree by nurse educators, but this varied greatly among nursing programs. The highest level of integration was found in fundamentals and medical-surgical courses, and the lowest level was found in nursing research courses (Altmiller \& Sullivan, 2017).

Altmiller and Sullivan (2017) noted that similar to previous studies (Barnsteiner et al., 2012; Peterson-Graziose \& Bryer, 2017), the competencies of safety, teamwork and collaboration, patient-centered care, and evidence-based practice were incorporated more often in nursing courses than informatics and quality improvement. Additionally, it is unclear if faculty are teaching updated QSEN competencies in their current curricula. The study found inconsistencies in the number of faculty trained in QSEN competencies, ranging from fully prepared to minimallyprepared. Barriers to integration of the competencies included lack of understanding, lack of time to learn about QSEN, and lack of resources. The need for teaching strategies to infuse quality and safety concepts into nursing curricula was an essential finding of this study.

The purpose of this research was to provide education, resources and support to nursing faculty in order for them to gain understanding and increase incorporation of the QSEN competencies in their nursing courses, and to determine the extent to which nursing faculty integrate QSEN competencies into the nursing curriculum. Inconsistencies among the number of faculty trained and differences in preparation demonstrate the need for organized, focused educational programs.

\section{Method}

A pretest-posttest design was used to measure faculty perceptions of the extent to which they teach the knowledge, skills, and attitudes associated with QSEN competencies in their nursing courses. Fulltime faculty were recruited during a monthly staff meeting. The time frame for this study was between fall 2018 and fall 2019. A non-probability convenience sample was used with no exclusions in gender, age, or ethnic background. Participants were asked to complete the National QSEN Faculty Survey before attending the first workshop, and again, one month after completing the six-part QSEN competency-based training course. The training course consisted of an electronic slide 
presentation, active learning strategies, references, and resources including the QSEN website. Descriptive statistics of frequency, range, mean, and median were used to analyze the demographic data. Pearson Chi-square was used to determine if there was any statistical significance to the distribution of responses for each of the QSEN competencies between the pretest and posttest groups. IRB approval was obtained and all subjects consented to participate in the study (approval code SKM_364e180914).

\section{Instrument}

The National QSEN Faculty Survey is a 19-item instrument with three items focused on demographics and the remainder measuring the integration of QSEN competencies into the respondent's nursing program. Additional aims of the survey include measuring the degree of faculty development in schools where QSEN is being used, and assessment of whether QSEN competencies are being taught in schools of nursing. The majority of questions were "select all that apply" format with two additional open-ended questions. The original 16-item survey was reviewed by a panel of experts for clarity and edits, tested in a small sample of nurse educators, and resulted in the 19-item instrument.

\section{Results}

A total of 19 faculty members, all female, participated in this study. Fifty percent of the participants reported less than 10 years teaching experience and $27 \%$ reporting teaching less than 5 years. The majority of faculty $(79 \%)$ reported teaching primarily in a prelicensure baccalaureate program. The remainder of the participants reported teaching primarily in a RN-BS program.

\section{Integration of QSEN Competencies}

Data were examined using Pearson Chi-Square to determine if there were any statistically significant differences between the distribution of responses for the pretest and posttest groups. While there were no statistically significant associations for integration of each of the competencies into the curriculum, most competencies showed an increase in integration. Pretest results reveal $90 \%$ of participants reported teaching patientcentered care, $84 \%$ evidence-based practice, $84 \%$ teamwork and collaboration and $89 \%$ safety in their courses. The competencies of quality improvement and informatics were reported to be the least integrated into the curriculum at $63 \%$ and $33 \%$ respectively. Posttest results show $100 \%$ of participants report teaching patientcentered care, and evidence-based practice, 93\% teamwork and collaboration and safety, and $73 \%$ quality improvement in their courses. The competency of informatics indicated slightly more integration in the pretest group (Figure 1). This may be due to a knowledge deficit related the meaning of the informatics competency.
Figure 1

\section{QSEN Competencies Covered in Pre Versus Post Group}

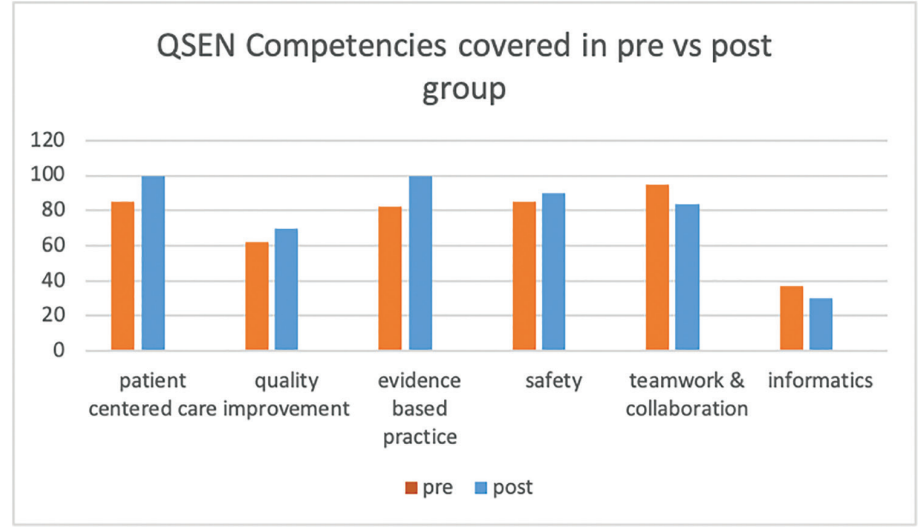

\section{Barriers to Faculty Learning}

One hundred percent of faculty reported that support from administration to learn the QSEN competencies was not a barrier to faculty learning. However, there were some other barriers to faculty learning identified. Pretest results showed almost half of the faculty-participants reported needing ideas for QSEN integration, and about one third reported challenges in getting colleagues to participate in integration. In response to an open-ended question about what would be helpful to successfully implement QSEN competencies into their nursing program, participants stated that ongoing continuing education programs or biannual workshops would be beneficial. Posttest results revealed a statistically significant change from pretest results in the response to "needing ideas for QSEN integration" $\left(\mathrm{X}^{2}=4.437, \mathrm{p}<0.05\right)$. The "need ideas for integration' is a less frequent barrier in the post group. Interestingly, "getting colleagues to participate in integration" of the competencies was perceived as more of a barrier after the workshop, with a $10 \%$ increase from pretest to posttest.

\section{Faculty Training}

At pretest, only $32 \%$ of faculty reported being trained in QSEN competencies. Posttest results revealed a statistically significant increase in the number of faculty who reported having received training $(90 \%)\left(X^{2}=12.616, p<0.05\right)$. Helpfulness of resources to assist with the integration of QSEN competencies into the curriculum was explored. Results revealed that the distribution of responses differed in a statistically significant way between pretest and posttest responses for the 'QSEN website' resource $\left(X^{2}=8.259, p<0.05\right)$, the 'QSEN video presentations' $\left(X^{2}=7.174\right.$, $\mathrm{p}<0.05)$, and the 'QSEN learning modules' resource $\left(\mathrm{X}^{2}=3.849\right.$, $\mathrm{p}<0.05)$. The increase in faculty response to the helpfulness of these resources between pretest and posttest is likely due to the training that the participants received during the faculty workshops highlighting the QSEN resources available to them.

\section{Teaching Setting}

Analysis was conducted to determine if there were any statistically significant differences to the distribution of the setting where QSEN competencies were taught between the pretest and posttest groups. Although the Pearson Chi-Square statistical test indicated that the distribution of responses did not differ 
significantly, 16 of the 19 faculty-participants reported teaching the competencies in the classroom during the pretest. Posttest results revealed a shift in the teaching setting, as faculty now reported an increase in lab teaching (21.1\% pretest/28.6\% posttest) and a decrease in classroom teaching $(n=16$ pretest $/ n=12$ posttest $)$. This may reflect an increased awareness or change in perspective of the QSEN competencies and the related knowledge, skills, and attitudes (Figure 2).

\section{Figure 2}

\section{Teaching Settings that QSEN Competencies were Integrated (Pre Versus Post Group)}

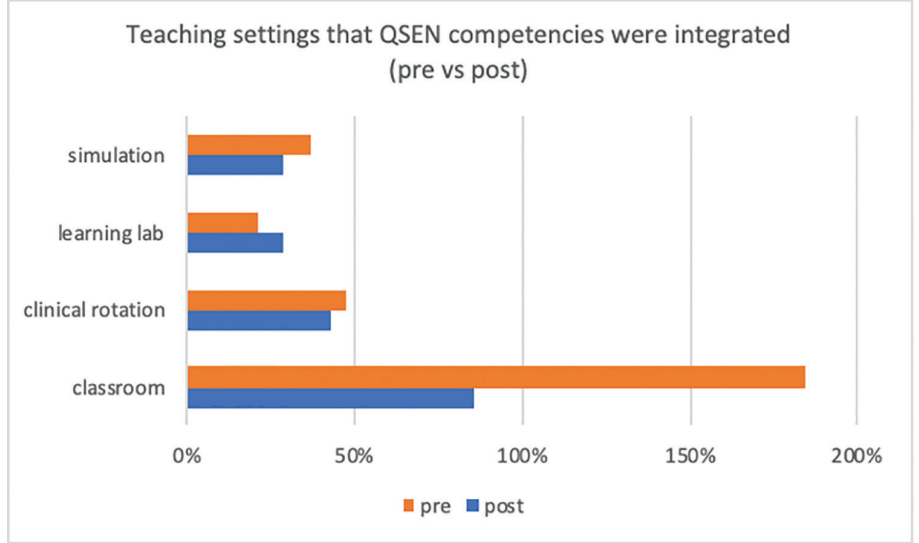

\section{Teaching Strategies}

A statistical analysis was conducted to determine whether responses for the effectiveness of the teaching strategy between the pretest and the posttest groups was significant. Using Pearson Chi-Square, findings indicated that the distribution of responses only differ in a statistically significant way across the pretest and posttest group for the 'case studies' teaching strategy, but only at the $90 \%$ level of significance $\left(\mathrm{X}^{2}=3.342, \mathrm{p}<0.1\right)$. Case studies were reported as a more effective teaching strategy among the posttest group ( $57.9 \%$ pretest $/ 86.7 \%$ posttest). This may be a result of faculty exposure to the case study strategy during the QSEN workshops.

Finally, analysis was conducted to determine if there was a statistically significant association between QSEN integration and the number of years in teaching. Using Pearson r, results indicated a positive correlation between the number of course content areas with QSEN competencies integrated and the number of years in teaching $(r=.435, \mathrm{p}<0.05)$. The greater the number of years of faculty teaching experience, the higher the number of course and content areas integrated.

\section{Discussion}

This research describes how full time faculty members teaching in a baccalaureate nursing program in the northeastern United States were surveyed to ascertain their perceptions of the integration of QSEN competencies in their nursing courses. Faculty were invited to participate in a six-part QSEN competencybased training workshop and complete the survey again. The majority of faculty reported integrating the QSEN competencies of patient-centered care, evidence-based practice, teamwork and collaboration and safety into their courses. The competencies of quality improvement and informatics were reported to be the least integrated. These results are congruent with findings from the literature (Altmiller \& Armstrong, 2017; Bryer \& PetersonGraziose, 2014). Barriers to integrating the QSEN competencies identified by nursing faculty include needing ideas for QSEN integration and getting colleagues to participate in integration. In fact, $100 \%$ of faculty reported strong administrative support to learn and integrate QSEN. Targeted educational programs emphasizing the informatics and quality improvement competencies may provide the necessary resources and support for faculty to gain understanding to increase incorporation of the competencies in their nursing courses. Surprisingly, only one third of the faculty reported being trained in QSEN competencies prior to attending the six-part QSEN competency-based training offered in this study. This highlights the need for ongoing, organized educational programs, and identification of resources for faculty to aid in the integration of QSEN competencies in nursing curricula. The open-ended responses underscored the need for supporting nursing faculty to effectively teach the QSEN competencies. Findings related to teaching strategies, specifically the increased use of case studies, may be reflective of faculty gaining a deeper understanding of the benefits of innovative, student-centered learning after attending the workshop. Additionally, faculty reported increased knowledge of the QSEN website resource, QSEN video presentations, and the QSEN learning modules resources after completing the training. Sustaining nursing faculty education in the QSEN initiative is of vital importance.

Prior to the QSEN workshops, findings indicated that the majority of faculty taught the QSEN competencies in the classroom setting. Broadening the faculty perspective on the variety of settings where the competencies can be integrated resulted in a decrease in classroom integration and an increase in learning lab integration. Introduction of possibilities for integration in less commonly used educational settings may foster faculty innovations and creativity in delivering quality and safety concepts. Interestingly, nurse educators with more years of experience were found to have more course and content area integration of QSEN competencies than faculty with fewer years of teaching experience. This may be a result of increased confidence in their teaching ability and their willingness to embrace current, evidence-based practice. Workshops led by experienced faculty may help overcome the barrier of getting colleagues to participate in integration. Shared ideas and experiences may provide support for newer faculty to expand integration of QSEN competencies in their own courses.

\section{Limitations}

There are several limitations to this study that must be considered. This study was conducted at one suburban college in the northeastern United States and the sample size was small. This may not be representative of all nursing faculty. There were four faculty who completed the pretest but did not complete the posttest which potentially could have impacted the results. 


\section{Summary}

There has been a concerted effort by nurse educators to integrate QSEN competencies into nursing curricula. Considering the findings in this study, the need for ongoing faculty development is evident. Many educators feel unprepared to teach quality and safety content in a way that reflects current practice, particularly the competencies of quality improvement and informatics. It is essential to provide faculty with continuing education, ideas for teaching strategies, and resources for meaningful and sustained integration of QSEN competencies in nursing curricula.

\section{References}

Altmiller, G., \& Armstrong, G. (2017). 2017 national quality and safety education for nurses faculty survey results. Nurse Educator, 42(58), 3-7. https://dx.doi.org/10.1097/ NNE.0000000000000408

Barnsteiner, J., Disch, J., Johnson, J., McGuinn, k., Chappell, K., \& Swartwout, E. (2012). Diffusing QSEN competencies across schools of nursing: The AACN/RWJF faculty development institutes. Journal of Professional Nursing, 29(2), 68-74. https://dx.doi.org/10.1016/j.profnurs.2012.12.003

Bryer, J., \& Peterson-Graziose, V. (2014). Integration of quality and safety competencies in undergraduate nursing education: A faculty development approach. Teaching and Learning in Nursing, 9(3), 130-133. https://dx.doi.org/10.1016/j. teln.2014.04.004

Cengiz, A., \& Yoda, L. (2020). Assessing nursing students' perceptions of the QSEN competencies: A systematic review of the literature with implications for academic programs. World Views on Evidence Based Nursing: Linking Evidence to Action, 17(4), 275-282. https://doi.org/10.1111/wvn.12458
Disch, J., Barnsteiner, J., \& McGuinn, K. (2013). Taking a “deep dive" on integrating QSEN content in San Francisco Bay area schools of nursing. Journal of Professional Nursing, 9 (2), 75 81. https://dx.doi.org/10.1016/j.profnurs.2012.12.007

Institute of Medicine (2001). Crossing the quality chasm: A new health system for the 21st century. National Academy Press

Lewis, M., \& Lamb, G. (2011). A comprehensive model for teaching Quality and Safety Education for Nurses (QSEN) competencies. Dean's Notes, 3(5), 1-3.

Makary, M. A., \& Daniel, M. (2016). Medical error-the third leading cause of death in the US. BMJ (Online), 353, [i2139]. https://dx.doi.org/10.1136/bmj.i2139

Peterson-Graziose, V., \& Bryer, J. (2017). Assessing student perceptions of quality and safety education for nurses competencies in a baccalaureate curriculum. Journal of Nursing Education, 6(7), 436-438. https://dx.doi. org/10.3928/01484834-20170619-09

Pollard, M.L., Stapleton, M., Kennelly, L., Bagdan, 1., Cannistraci, P., Millenbach, L. \& Odondi, M. (2014). Assessment of quality and safety education in nursing: A New York State perspective. Nursing Education Perspectives, 35(4), 224-229. https:// dx.doi.org/10.5480/13-1104.1

Sullivan, D.T., Hirst, D., \& Cronenwett. L. (2009). Assessing quality and safety competencies of graduating prelicensure nursing students. Nursing Outlook, 57, 323-331. https://dx.doi. org/10.1016/j.outlook.2009.08.004

Tovar, E., Ossege, J., Farus-Brown, S., Zonsius, M. \& Morrow, L. (2019). DNP program faculty and graduates' knowledge and use of QI and safety processes. Nurse Educator, 45(1), 11-16. https://dx.doi.org/10.1097/NNE.0000000000000677 